kwashiorkor. Brit. J. Nutr., 29: 399 (1973).

27. Mann, M. D., Becker, D. J., Pimstone, B. L., and Hansen, J. D. L.: Potassium supplementation, serum immunoreactive insulin concentrations and glucose tolerance in protein-energy malnutrition. Brit. J. Nutr., 33: 55 (1975).

28. Marks, V., Howorth, N., and Greenwood, F. C.: Plasma growth hormone levels in chronic starvation in man. Nature, 208: 686 (1965).

29. Melichar, V., Novak, M., Hahn, P., and Koldovsky, O.: Free fatty acid and glucose in the blood of various groups of newborns. Preliminary Report. Acta Paediat., 53: 343 (1964).

30. Merimee, T. J., Felig, P., Marliss, E., Fineberg, S. E., and Cahill, G. F., Jr.: Glucose and lipid homeostasis in the absence of human growth hormone. J. Clin. Invest., 50: 574 (1971).

31. Milner, R. D. G.: Metabolic and hormonal responses to glucose and glucagon in patients with infantile malnutrition. Pediat. Res., 5: 33 (1971).

32. Milner, R. D. G.: Metabolic and hormonal responses to oral amino acids in infantile malnutrition. Arch. Dis. Childhood, 46: 301 (1971).

33. Milunsky, A., Bray, G. A., Londono, J., and Loridan, L.: Insulin, glucose, growth hormone, and free fatty acids. Determination in patients with cystic fibrosis. Amer. J. Dis. Child., 121: 15 (1971).

34. Mönckeberg, F., Donoso, G., Oxman, S., Pak, N., and Meneghello, J.: Human growth hormone in infant malnutrition. Pediatrics, 31: 58 (1963).

35. Nelson, N.: A photometric adaptation of the Somogyi method for the determination of glucose. J. Biol. Chem., 153: 375 (1944).

36. Parra, A., Garza, C., Garza, Y., Saravia, J. L., Hazelwood, C. F., and Nichols, B. L.: Changes in growth hormone, insulin, and thyroxine values, and in energy metabolism of marasmic infants. J. Pediat., 82: 133 (1973).

37. Pickens, J. M., Burkeholder, J. N., and Womack, W. N.: Oral glucose tolerance test in normal children. Diabetes, 16: 11 (1967).

38. Pimstone, B. L., Barbezat, G., Hansen, J. D. L., and Murray, P.: Growth hormone and protein-calorie malnutrition. Lancet, $i i: 1333$ (1967).

39. Pimstone, B. L., Barbezat, G., Hansen, J. D. L., and Murray, P.: Studies on growth hormone secretion in protein-calorie malnutrition. Amer. J. Clin. Nutr., 21: 482 (1968).
40. Pimstone, B. L., Wittman, W., Hansen, J. D. L., and Murray, P.: Growth hormone and kwashiorkor. Lancet, ii: 779 (1966).

41. Prinsloo, J. G., DeBruin, E. J. P., and Kruger, H.: Comparison of intravenous glucose tolerance tests and serum insulin levels in kwashiorkor and pellagra. Arch. Dis. Childhood, 46: 795 (1971).

42. Raghuramulu, N., and Jaya Rao, K. S.: Growth hormone secretion in protein-calorie malnutrition. J. Clin. Endocrinol. Metab., 38: 176 (1974).

43. Randle, P. J., Garland, P. B., Hales, C. N., and Newsholme, E. A.: The glucose fatty-acid cycle. Its role in insulin sensitivity and the metabolic disturbances of diabetes mellitus. Lancet, $i: 785$ (1963).

44. Samuel, A. M., and Deshpande, U. R.: Growth hormone levels in protein calorie malnutrition. J. Clin. Endocrinol Metab. 35: 863 (1972).

45. Schalch, D. S., and Parker, M. L.: A sensitive double antibody immunoassay for human growth hormone in plasma. Nature, 203: 1141 (1964).

46. Sukkar, M. Y., Hunter, W. M., and Passmore, R.: Changes in plasma levels of insulin and growth hormone levels after a protein meal. Lancet, ii: 1020 (1967).

47. Yalow, R. S and Berson, S. A. Immunoassay of endogenous plasma insulin in man. J. Clin. Invest., 39: $1157(1960)$

48. Zierler, K. L., and Rabinowitz, D.: Effect of very small concentrations of insulin on forearm metabolism. Persistence of its action on potassium and free fatty acids without its effect on glucose. J. Clin. Invest., 43: 950 (1964).

49. Informed consent was obtained for all subjects in this study.

50. This research was supported in part by Research Grants AM-09980 and HD-01852 from the National Institutes of Health, United States Public Health Service, and Research Contract csd-2946 with the Agency for International Development, United States Department of State.

51. The present address of Dr. R. G. Thompson is: Department of Pediatrics, University of Iowa School of Medicine, Iowa City, Iowa.

52. The present address of Dr. R. M. Blizzard is: Department of Pediatrics, University of Virginia School of Medicine, Charlottesville, Virginia.

53. Requests for reprints should be addressed to: George G. Graham, M. D., 615 North Wolfe St., Baltimore, Md. 21205 (USA).

54. Accepted for publication May 7, 1976.

\title{
A Behavioral Phenotype in the de Lange Syndrome
}

\author{
HAROLD G. JOHNSON, PAUL EKMAN, AND WALLACE FRIESEN \\ Human Interaction Laboratory, University of California San Francisco, San Francisco, California
}

WILLIAM L. NYHAN ${ }^{(20)}$

Department of Pediatrics, University of California San Diego, San Diego, California

CAROL SHEAR

Mailman Center, Department of Pediatrics, University of Miami, Miami, Florida, USA

\section{Extract}

The behavior of nine patients with the de Lange syndrome was studied using videotape, a recording protocol of eight standardized stimulus conditions, and a visual, digital time reference which permitted precise coding and quantitative analysis. These patients avoid or reject social interactions and physical contact, and they do not distinguish in this between a stranger and the mother or her substitute. Social interactions with the adult stranger were scored in patients $1-7$ as negative for $28-56 \mathrm{sec} / \mathrm{min}$, whereas they were positive for 1-6 sec/min. Statistical significance was at the level of $P$ $<0.01$. In the case of the mother negative responses ranged from $21-45 \mathrm{sec} / \mathrm{min}$ and positive from 3-27 $\mathrm{sec} / \mathrm{min}$. The patients exhibit infrequent facial expressions of emotion, and frequently display stereotypic movements. On the other hand, vestibular stimulation or vigorous movement appeared to be an effective means of eliciting pleasurable responses. When held in arms in the vertical position only one of nine children smiled at all and the frequency for that child was $0.8 / \mathrm{min}$. When the child was bounced vigorously in the same position, all smiled but one who was too large to be bounced. In the eight the frequency of smiling ranged from 0.8 $3.6 / \mathrm{min}$. The data obtained indicate that a specific behavioral phenotype is associated with this syndrome.

\section{Speculation}

It seems clear that there is a distinct behavioral phenotype in the de Lange syndrome. We believe that this is only one of many such patterns of behavior that characterize children with clinical syndromes. The delineation of these phenotypes should provide important evidence on somatic determinants of behavior. 
Among populations of retarded children there are a number of syndromes in which highly distinctive anatomic characteristics permit diagnosis and categorization. Our experience and that of others led us to believe that there were also distinctive behavioral syndromes or behavioral phenotypes (11) among those populations of patients in which the physical phenotype is distinct. If behavioral phenotypes can be defined in organic disorders in which somatic morphology is striking, it is likely that it will eventually be possible to define within the central nervous system anatomic, electrophysiologic, or chemical concomitants of the behavior.

This study was an attempt to define rigorously a behavioral phenotype for a distinct group of patients. It was designed to assess the possibility that a distinctive set of behavior patterns is present among patients with the syndrome described by Cornelia de Lange (4). An additional objective was to establish a method for the quantitative description of behavior. A method employing videotape recordings with a continuous visual time reference superimposed was used (6).

\section{MATERIALS AND METHODS}

Observations have been made on videotape on 13 patients with the de Lange syndrome. From initial observations and from videotape of three of the subjects, we developed a series of descriptive hypotheses. Others were developed through interactions among the investigators and with the patients and their families. Out of these a protocol was developed for videotaping. Two patients originally studied on videotape died during the period of planning the formal protocol. Detailed studies were carried out on 11 subjects. Two of these were infants and required considerable modification of the protocol. Therefore it was decided to submit the remaining cohort of nine patients to fine-grained analysis of their behavior patterns.

There were six males and three females. Their ages ranged from 5-25 years. We considered all but one to have been reared at home. One subject (subject 4) had spent his entire life in institutions. Subject 2 had been institutionalized for the most recent 2 years of his life. All the rest were living at home. Three were from the East Coast, three from the Midwest, and three from the West Coast. No subject had any social contact with another before the recording sessions. Each subject was in a studio recording session over a period of $4 \mathrm{hr}$, which yielded $45-60 \mathrm{~min}$ of videotaped behavioral record. Detailed analysis was carried out for only those sequences that were repeated across the entire subject sample.

The descriptive hypotheses we developed were that the following behavioral features were characteristic of patients with the de Lange syndrome: $(1)$ lack of speech; (2) infrequent display of facial expression of emotion; (3) little attention to the environment; (4) an absence of social interaction with other persons whether strangers or familiar persons; (5) an aversive response to physical contact; (6) indulgence in repetitive activity, usually of a selfstimulatory nature, and sometimes of a self-mutilative nature; (7) positive responses to vigorous motion stimulation.

\section{RECORDING PROTOCOL}

An operating protocol with eight major stimulus conditions (SC) was developed to test the descriptive hypotheses. The stimulus conditions have been numbered $S C-1$ through $S C-8$.

\section{SC-1: BASELINE, SUBJECT ALONE}

\section{SC-2: ADULT STRANGER, SOCIAL INTERACTIONS AND PHYSICAL.} CONTACT

There was a gradually increasing progression of human interaction and degree of physical contact, proceeding from visual to auditory to tactile stimulation.

$S C-2 A$ : Calling. The adult, female stranger used gestures, speech, and greeting behavior in an attempt to elicit social interactive responses from the subject.

$S C-2 B$ : Walking. The adult took the child's hand and walked with him around the room still talking but now introducing closer physical proximity and the minimal contact of holding one hand.

$S C-2 C$ : Patting. This sequence was designed to provide a much greater degree of physical contact. The subject was ultimately held encircled within the adult's arms with both standing.

\section{SC-3: ADULT STRANGER, XYLOPHONE ROUTINE}

The primary purpose of this episode was to introduce an interesting task-object-a bright, multicolored xylophone-that could involve the child in a directed motor activity.

\section{SC-4: ADULT STRANGER, PICK UP AND HOLD}

$S C-4 A$ : Pick up, Horizontal. The subject was picked up in a horizontal position cradled in the adult's arms to assess whether he would "cuddle" during a typical interaction of a mother and child.

$S C-4 B$ : Pick Up, Vertical. The subject was picked up in a vertical or a "burping" position, head up and facing the other person.

\section{SC-5: ADULT STRANGER, JACK-IN-THE-BOX ROUTINE}

Three jack-in-the-box toys with a clown head, cat head, and no head were used to attempt to elicit surprise.

\section{SC-6: ADULT STRANGER, SWING AND BOUNCE}

$S C-6 A$ : Swinging. The subject was picked up horizontally as in $S C-4 A$ but was also vigorously rocked back-and-forth to see if the behavior changed with added kinesthetic/vestibular stimulation.

$S C-6 B$ : Bouncing. The subject was picked up vertically as in $S C-4 B$ but also vigorously bounced up and down.

\section{SC-7: FAMILIAR PERSON, SOCIAL INTERACTION AND PHYSICAL CONTACT}

$S C-7 A$ : Calling. A replication of $S C-2 A$ with the mother or other familiar person as the interactant.

$S C-7 B$ : Walking. Replication of $S C-2 B$ with familiar person.

$S C-7 C$ : Patting. Replication of $S C-2 C$ with familiar person.

$S C-7 D$ : Picking up. This sequence was designed to replicate $S C-4 A$ and $S C-4 B$ but varied so with the weight of the child and physical capacity of the mother that comparative data could not be obtained.

\section{SC-8: ADULT STRANGER, TWIRLING SUBJECT IN SWIVEL CHAIR}

This sequence was divided into time periods in which the subject was being twirled and stopped.

SC-8A: Twirling. Preliminary observations had suggested the twirling kinesthetic/vestibular stimulation was pleasant (1).

SC-8B: Twirling stopped. These were time periods just after subject had been twirled with the "agent" standing close to the chair. We measured whether the stimulation tended to increase social responses toward the agent who could provide subsequent reinforcement.

\section{CODING AND ANALYSIS OF VIDEOTAPES}

Four major classes of behavior were measured across the stimulus conditions: interactions with people and with taskobjects; speech and auditory behavior; facial expression; and repetitive or stereotypic activity. Behavior was coded into categories that could be clearly recognized on the tapes and measured quantitatively in terms of both frequency and duration.

The coding unit was used as an "act" which is defined as any facial or body movement with an observable beginning and end. The visual, digital time reference included in each of the tapes permitted the measurement of the frequency and duration of each act with an accuracy to $1 \mathrm{sec}$. The visual time reference can be seen in Figures 1-4. The frequency and duration data were transformed to frequency per minute $(\mathrm{f} / \mathrm{min})$ and seconds per minute $(\mathrm{sec} / \mathrm{min})$ to correct for the fact that different subjects spent varying periods 


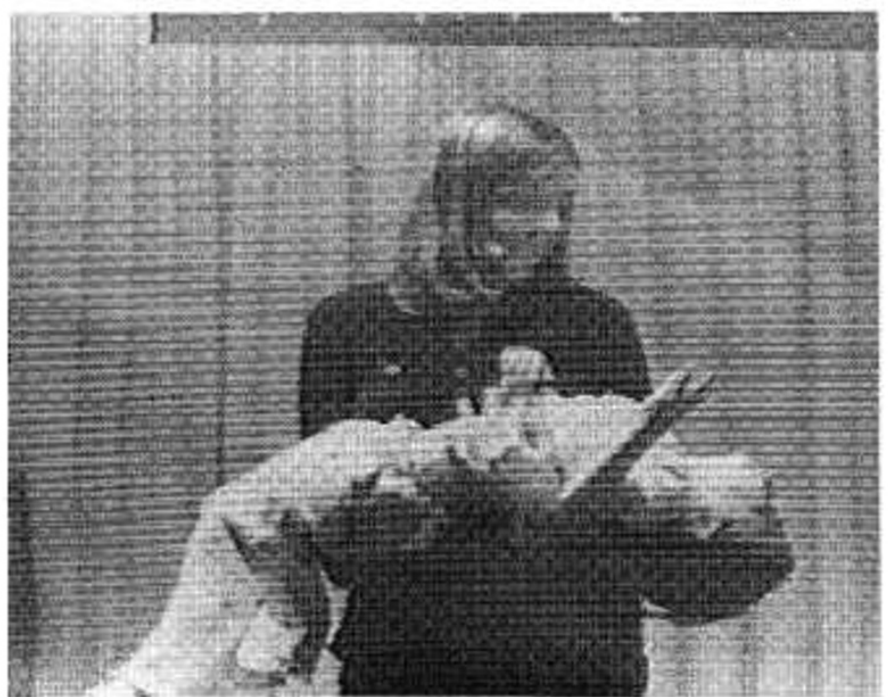

Fig. 1. The de Lange arch in response to being held. The photograph and the next subsequent illustrations were taken off the video monitor to illustrate the technique. The visual time reference is evident.

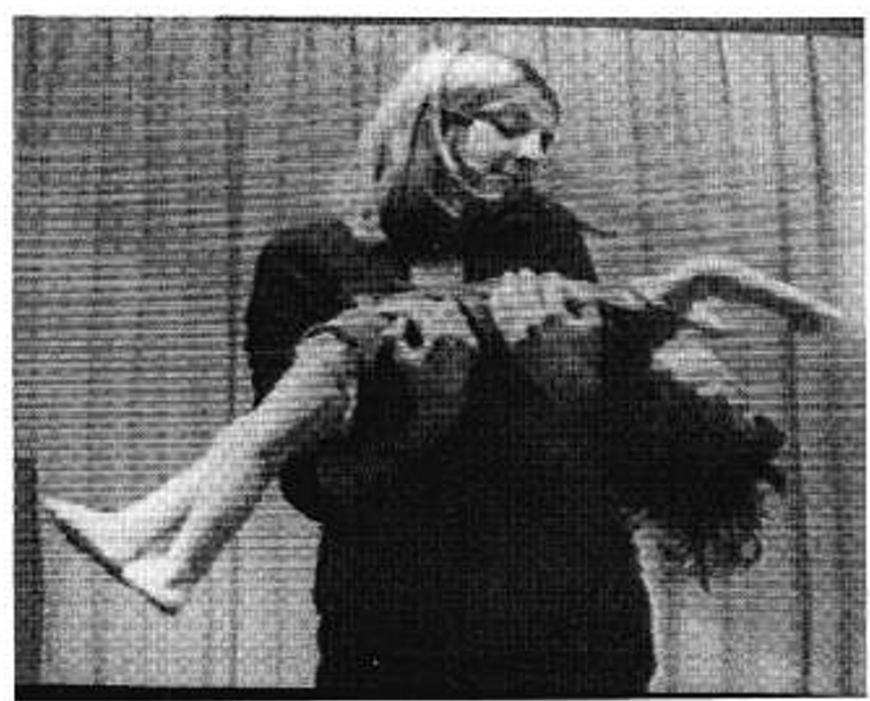

Fig. 2. A second subject demonstrates this arching behavior.

of time in a given stimulus condition. Seconds per minute indicate the number of seconds the subject engaged in the behavior divided by the number of minutes recorded for that condition. This analytic procedure provided equivalent data across subjects. The reliability of data in which distinctions of this type have been made from videotape has been documented. Investigators have generally reported average inter-rater reliability coefficients above $0.80(2$, 5) even in more complex and subtle differentiations.

These experiments were conducted in accordance with institutional regulations concerning human experimentation in each of the three collaborating institutions. Informed consent was obtained from the responsible parent or guardian in each instance. Signed permission was obtained for the release and publication of photographs of the subjects.

\section{RESULTS}

The data were considered in terms of each of the descriptive hypotheses. In general, the frequency data were highly correlated with the duration data.

\section{SOCIAL INTERACTIVE BEHAVIOR-COMPARISON OF ADULT STRANGER WITH FAMILIAR PERSON}

Social interactive responses are summarized in Table 1 . Responses to the adult stranger and the familiar person are com- pared. The behaviors coded were judged as being "positive" or "negative" social interactions. Movements toward another person and the act of facing or looking at the other person's face were considered positive. Negative social interactions were those in which the subject moved away from the other person. An unusual and characteristic response, when the subject was held, was to arch his back or body in an almost opisthotonic position away from the person holding him; this was coded as negative (Figs. 1 and 2).

In these subjects, there was a general paucity of social responses. In subjects $1-7$ negative responses exceeded positive ones for both the adult stranger and the familiar person (Table 1, comparisons A and C). In subjects 8 and 9 the behavior pattern was reversed and positive responses exceeded negative. These were the only two subjects that had any speech. Subject 8 spoke using short sentences, while subject 9 had three one-word utterances. Responses to the "adult stranger" were compared with those to the "familiar person." Negative responses dominated both sets of situations. There was no difference in behavior to the adult stranger or the familiar person (comparison $\mathrm{J}$ ).

\section{ACCEPTANCE/REJECTION OF PHYSICAL/TACTILE CONTACT WITH ADULT STRANGER}

In our initial observations, one of the most impressive things about the behavior of the child with the de Lange syndrome was his tendency to arch his back and turn away from an adult who attempted to pick him up and cuddle him (Figs. 1 and 2). Data on

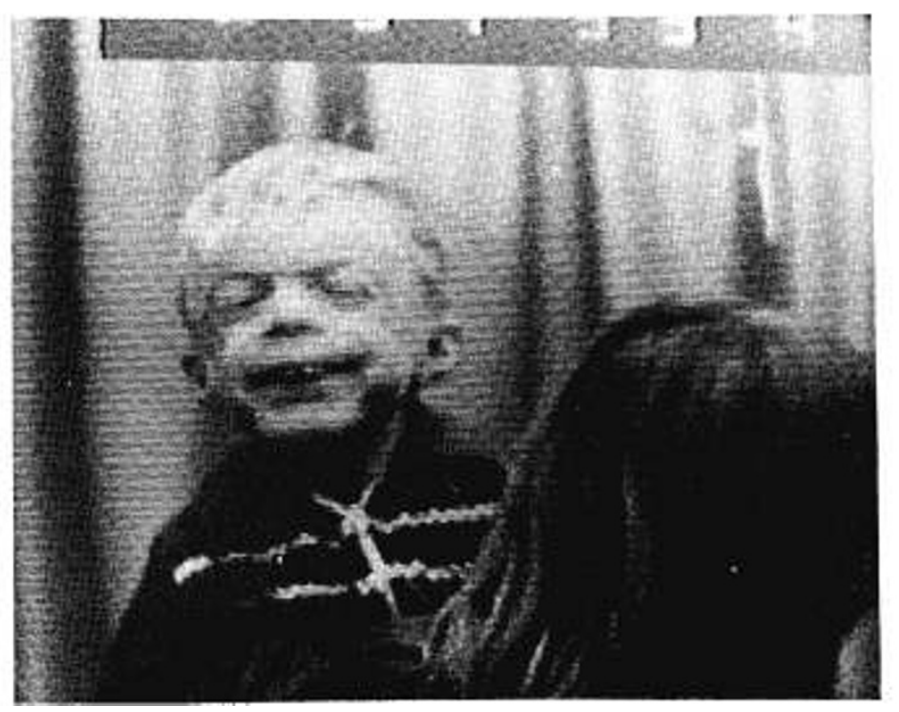

Fig. 3. A smile. The motion that generated it is evident.

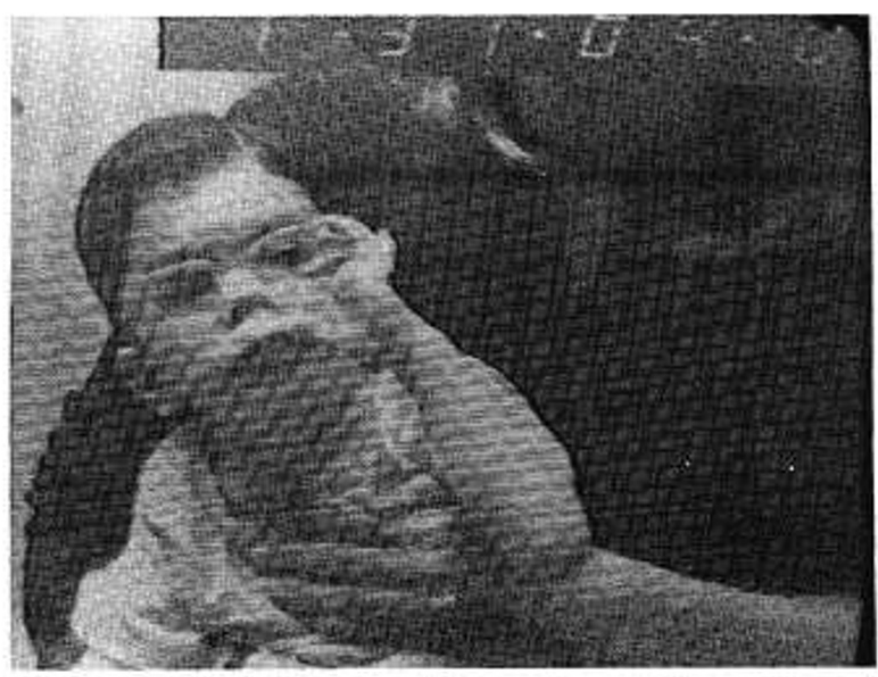

Fig. 4. Hand posturing. 
Table 1. Social interactions ${ }^{1}$

\begin{tabular}{|c|c|c|c|c|c|c|}
\hline \multirow[b]{2}{*}{ Subject } & \multirow[b]{2}{*}{ Sex } & \multirow[b]{2}{*}{ Age } & \multicolumn{2}{|c|}{$\begin{array}{l}\text { Adult stranger, } \\
\mathrm{sec} / \mathrm{min}\end{array}$} & \multicolumn{2}{|c|}{$\begin{array}{c}\text { Familiar person, } \\
\mathrm{sec} / \mathrm{min}\end{array}$} \\
\hline & & & $\begin{array}{l}\text { Posi- } \\
\text { tive }\end{array}$ & $\begin{array}{l}\text { Nega- } \\
\text { tive }\end{array}$ & $\begin{array}{l}\text { Posi- } \\
\text { tive }\end{array}$ & $\begin{array}{l}\text { Nega- } \\
\text { tive }\end{array}$ \\
\hline$I$ & $\mathrm{~F}$ & 9 & 16.4 & 36.1 & 25.2 & 34.7 \\
\hline 2 & M & 12 & 6.0 & 54.0 & 6.8 & 44.6 \\
\hline 3 & M & 24 & 6.9 & 41.3 & 20.4 & 31.2 \\
\hline 4 & $F$ & 13 & 14.7 & 45.2 & 3.5 & 20.5 \\
\hline 5 & $M$ & 5 & 1.2 & 56.2 & 14.8 & 30.0 \\
\hline 6 & M & 6 & 2.9 & 28.0 & 2.5 & 27.7 \\
\hline 7 & M & 5 & 15.8 & 36.5 & 27.1 & 23.3 \\
\hline 8 & $\begin{array}{l}\text { M } \\
\text { (S } \\
\text { bel }\end{array}$ & $\begin{array}{l}14 \\
\text { ior) }\end{array}$ & 58.1 & 0.0 & 44.2 & 0.0 \\
\hline 9 & $\begin{array}{l}\mathrm{F} \\
(\mathrm{M} \\
\mathrm{sp}\end{array}$ & $\begin{array}{l}12 \\
\text { mal } \\
\text { ch) }\end{array}$ & 25.6 & 9.2 & 50.1 & 5.2 \\
\hline
\end{tabular}

${ }^{1}$ Statistical comparisons-Wilcoxon $T$ :

n $\quad$ T $\quad P$

\begin{tabular}{lrrc}
\hline Adult stranger & & & \\
A. Neg. vs. Pos. & 7 & 0 & $<0.01$ \\
B. Neg.vs. Pos. & 9 & 10 & n.s. \\
Familiar person & & & \\
C. Neg. vs. Pos. & 7 & 1 & $<0.025$ \\
D. Neg. vs. Pos. & 9 & 18 & n.s. \\
Stranger with familiar & 7 & 7 & n.s. \\
E. Pos. vs. Pos. & 9 & 15 & n.s. \\
F. Pos. vs. Pos. & 7 & 0 & $<0.01$ \\
G. Neg. vs. Neg. & 9 & 0 & $<0.01$ \\
H. Neg. vs. Neg. & & & \\
J. Neg./Pos. vs. Neg./Pos. & 7 & 7.5 & n.s.
\end{tabular}

this point are provided in Table 2 where the frequency of arching of the back in response to being cradled has been tabulated.

Again, subjects 8 and 9 were different. All of the others arched when held horizontally instead of cuddling toward the adult as one expects a child to do. Arching was also regularly observed when these patients were held vertically but it was unreliably recorded on camera.

We also coded the overall pattern of social interaction in these situations (Table 3 ). The general pattern was of primarily negative social responses. In overall interpretation of Tables 2 and 3 it is clear that picking these children up in the standard rock-a-bye baby position leads to withdrawal and negative social behavior. This is an unusual response to this situation. The data in Table 4 consider the same types of interaction with the child in a vertical or burping position. Again, the overall impression was of negative responses to being held, but holding in this position appeared to be much less aversive than the horizontal position.

The effects of introducing a bouncing motion in the vertical babe-in-arms position were rather striking. Significantly, more positive responses were seen in every subject (Table 4 , comparisons $\mathrm{C}$ and $\mathrm{D}$ and $\mathrm{E}$ and $\mathrm{F}$ ). An enormous amount of smiling behavior for these children was observed (Fig. 3). We had never seen children with this syndrome light up so before. Audible laughing was heard in this situation and not elsewhere in work with these children. There was also a great decrease in negative responses and no cry/sad expressions. Rather vigorous bouncing motion in this position was clearly pleasurable. These observations could have implications for advice to parents in management and the elicitation of positive social responding. Our adult stranger found that in this sequence she began to get feedback responses from these children for the first time. This pattern tended to reinforce her behavior and she bounced more vigorously leading to more responses by the subjects.

\section{MOTION STIMULATION WITHOUT PHYSICAL/TACTILE STIMULATION}

We next assessed the influence of motion without the other stimuli of human tactile contact and holding. In pilot studies we had observed that twirling a patient with the de Lange syndrome in a standard swivel chair led to positive responses.

We compared the social behavior sequence $S C$-2 in which the stranger attempted to elicit social responses with typical speech gestures and tactile stimulation with periods in sequence $S C-8$ in which the twirling had just stopped. These data show that social responses were much less negative after twirling (Table 5, comparisons $G$ and $H$ ). There was for these children quite a lot of smiling during the actual turning in the chair. Little continued over into the post-twirl period (Table 6). We have thought that spontaneous turning on the part of these children as they walk and stand (9) might be an attempt on their part at self-generation of the same stimuli they get in the chair.

\section{ATTENTION TO NONSOCIAL ENVIRONMENT}

Two situations were introduced in which brightly colored, sound-producing objects (the xylophone $(S C-3)$ and the jack-inthe-box $(S C-5)$ were used in order to see if the subjects could maintain sustained interest in their external environment. The data for $S C-3$ and $S C-5$ were very similar and are combined in Table 7 . Most subjects paid considerable attention to the task objects and little attention to the person (Table 7, comparisons A and B). This was somewhat surprising in that their histories had indicated that they did not play with objects and tended to be oblivious to their environments. Both task objects had sounds that rewarded attention, and the adult directed their activities. These results demonstrate that it is possible to hold the attention of children with the de Lange syndrome and one can get them to participate. These observations could have implications for the teaching of these children.

\section{SPEECH AND AUDITORY BEHAVIOR}

Speech is not a characteristic of this syndrome. Only subjects 8 and 9 had any speech at all, and they turned out to be quite

Table 2. Frequency of apparent rejection-arching of back when held $^{1}$

\begin{tabular}{ccc}
\hline & \multicolumn{2}{c}{ Arch back, f/min } \\
\cline { 2 - 3 } Subject & Horizontal holding & Horizontal swinging \\
\hline 1 & 6.9 & 2.0 \\
2 & 1.0 & 4.0 \\
3 & 8.0 & 15.0 \\
4 & 2.1 & 4.2 \\
5 & 20.6 & 2.5 \\
6 & 1.1 & 0.6 \\
7 & 1.5 & 0.0 \\
& & 0.0 \\
9 & 0.0 & 0.0 \\
\hline
\end{tabular}

\begin{tabular}{lllll}
\hline \multicolumn{1}{c}{ Statistical comparisons-Wilcoxon $T$ : } & & & \\
\hline & $n$ & $T$ & $P$ \\
\hline A. Horizontal vs. swinging & 7 & 13 & n.s. \\
B. Horizontal vs. swinging & 9 & 13 & n.s. \\
\hline
\end{tabular}


Table 3. Comparison of Positive (Pos.) and negative (Neg.) social behavior when held horizontally ${ }^{1}$

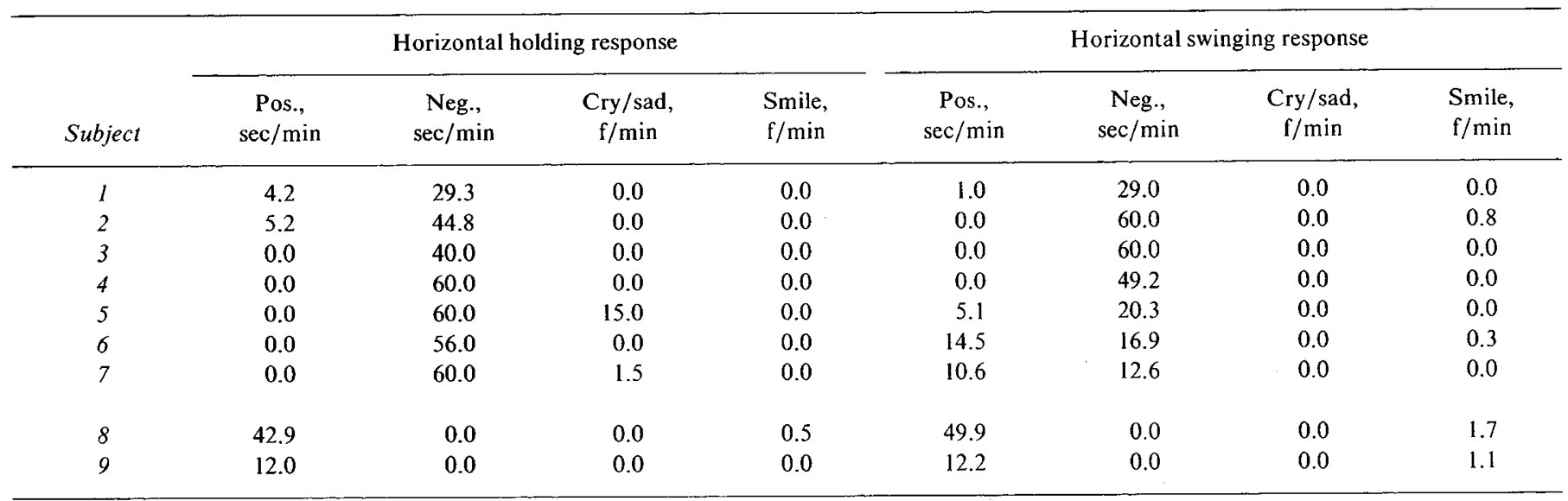

${ }^{1}$ Statistical comparisons-Wilcoxon $T$ :

\begin{tabular}{|c|c|c|c|c|c|c|c|}
\hline & $n$ & $T$ & $P$ & & $n$ & $T$ & $T$ \\
\hline Horizontal & & & & Horizontal with swinging & & & \\
\hline A. Neg. vs. Pos. & 7 & 0 & $<0.01$ & E. Neg. vs. Neg. & 7 & 7 & n.s. \\
\hline B. Neg. vs. Pos. & 9 & 6 & n.s. & F. Neg. vs. Neg. & 9 & 7 & n.s. \\
\hline Swinging & & & & G. Pos. vs. Pos. & 7 & 4 & n.s. \\
\hline C. Neg.vs. Pos. & 7 & 0 & $<0.01$ & H. Pos. vs. Pos. & 9 & 4 & n.s. \\
\hline D. Neg. vs. Pos. & 9 & 10 & n.s. & & & & \\
\hline
\end{tabular}

Table 4. Comparison of positive (Pos.) and negative (Neg.) social responses to holding vertically

\begin{tabular}{|c|c|c|c|c|c|c|c|c|}
\hline \multirow[b]{2}{*}{ Subject } & \multicolumn{4}{|c|}{ Vertical holding response } & \multicolumn{4}{|c|}{ Vertical bouncing response } \\
\hline & $\begin{array}{c}\text { Pos., } \\
\mathrm{sec} / \mathrm{min}\end{array}$ & $\begin{array}{l}\text { Neg., } \\
\mathrm{sec} / \mathrm{min}\end{array}$ & $\begin{array}{l}\text { Cry/sad, } \\
\text { f/min }\end{array}$ & $\begin{array}{l}\text { Smile, } \\
\mathrm{f} / \mathrm{min}\end{array}$ & $\begin{array}{l}\text { Pos., } \\
\mathrm{sec} / \mathrm{min}\end{array}$ & $\begin{array}{l}\text { Neg., } \\
\mathrm{sec} / \mathrm{min}\end{array}$ & $\begin{array}{c}\text { Cry/sad, } \\
\text { f/min }\end{array}$ & $\begin{array}{l}\text { Smile, } \\
\mathrm{f} / \mathrm{min}\end{array}$ \\
\hline 1 & 18.0 & 20.6 & 0.0 & 0.0 & 60.0 & 0.0 & 0.0 & 3.6 \\
\hline 2 & 0.0 & 0.0 & 0.0 & 0.0 & 20.2 & 39.8 & 0.0 & 0.8 \\
\hline 3 & 47.1 & 0.0 & 0.0 & 0.0 & 60.0 & 0.0 & 0.0 & 2.6 \\
\hline 4 & 0.0 & 60.0 & 0.0 & 0.0 & 38.5 & 13.7 & 0.0 & 1.7 \\
\hline 5 & 0.0 & 6.2 & 0.0 & 0.8 & 20.2 & 0.0 & 0.0 & 1.3 \\
\hline 6 & 0.8 & 53.4 & 0.0 & 0.0 & 60.0 & 0.0 & 0.0 & 0.9 \\
\hline 7 & 60.0 & 0.0 & 0.0 & 0.0 & 60.0 & 0.0 & 0.0 & 1.9 \\
\hline 8 & 22.0 & 0.0 & 0.0 & 0.0 & 55.4 & 0.0 & 0.0 & 1.8 \\
\hline 9 & 15.9 & 0.0 & 3.5 & 0.0 & 60.0 & 0.0 & 0.0 & 0.0 \\
\hline
\end{tabular}

${ }^{1}$ Statistical comparisons-Wilcoxon $T$ :

\begin{tabular}{|c|c|c|c|c|c|c|c|}
\hline & $n$ & $T$ & $P$ & & $n$ & $T$ & $P$ \\
\hline Vertical holding & & & & Hold with Bounce & & & \\
\hline A. Neg. vs. Pos. & 7 & 8.5 & n.s. & E. Pos. vs. Pos. & 7 & 0 & $<0.01$ \\
\hline B. Neg. vs. Pos. & 9 & 16.5 & n.s. & F. Pos. vs. Pos. & 9 & 0 & $<0.01$ \\
\hline \multicolumn{8}{|l|}{ Vertical bouncing } \\
\hline C. Neg. vs. Pos. & 7 & 1 & $<0.01$ & G. Neg. vs. Neg. & 7 & 3 & n.s. \\
\hline D. Neg. vs. Pos. & 9 & 1 & $<0.01$ & H. Neg. vs. Neg. & 9 & 3 & n.s. \\
\hline
\end{tabular}

different from the others in virtually every behavior analyzed. Subject 8 responded to questions with two- to three-word sentences or, more often, simply with "yes" or "no." Subject 9 had three one-word responses: two instances of a slurred "more," and "Mama" once. Neither talked much but even this much speech was very different from all the rest.

An intriguing possibility is that the presence of speech indicates heterogeneity in the syndrome.

The other seven subjects made noises or vocalizations that could be described as deep or raucous grunting sounds. Some subjects had a sort of babbling, monotonous, repetitive sound.

\section{EXPRESSIONS OF EMOTION ON FACES}

These subjects were notable for their lack of facial expression. The baseline face was impassive, and they seldom deviated from baseline. Specifically, there were almost no movements of the eyebrows or the upper areas of the face.

There are six facial expressions generally designated as associated with primary emotions. These are: happy, sad, surprise, fear, disgust, and anger. Only smile/happy and cry/sad expressions were observed, although random self-stimulatory movements of the mouth also occurred. The smile/happy and cry/sad sequences 
Table 5. Comparison of usual social behavior with that after twirling in chair

\begin{tabular}{cccccccc}
\hline & \multicolumn{2}{c}{ Sequences $S C-2 A, B, C$} & & \multicolumn{3}{c}{$S C-8 B$, twirling stopped } \\
\cline { 2 - 3 } $\begin{array}{c}\text { Sub- } \\
\text { ject }\end{array}$ & $\begin{array}{c}\text { Facing, } \\
\text { f/min }\end{array}$ & $\begin{array}{c}\text { Pos., } \\
\text { sec/min }\end{array}$ & $\begin{array}{c}\text { Neg., } \\
\text { sec/min }\end{array}$ & $\begin{array}{c}\text { Facing, } \\
\text { f/min }\end{array}$ & $\begin{array}{c}\text { Pos., } \\
\text { sec/min }\end{array}$ & $\begin{array}{c}\text { Neg., } \\
\text { sec/min }\end{array}$ \\
\hline 1 & 4.2 & 16.4 & 36.1 & & 0.0 & 0.0 & 5.8 \\
2 & 0.9 & 6.0 & 54.0 & 3.6 & 19.4 & 0.0 \\
3 & 2.7 & 6.9 & 41.3 & 3.0 & 12.0 & 27.0 \\
4 & 0.4 & 14.7 & 45.2 & 2.8 & 28.4 & 16.1 \\
5 & 0.8 & 1.3 & 56.2 & 2.6 & 3.2 & 56.8 \\
6 & 0.4 & 2.9 & 28.0 & 3.4 & 6.2 & 0.7 \\
7 & 1.3 & 15.8 & 36.5 & 2.1 & 2.8 & 0.0 \\
8 & 8.9 & 58.1 & 0.0 & 5.8 & 26.3 & 0.0 \\
9 & 1.3 & 25.6 & 9.6 & 1.5 & 13.9 & 3.7 \\
\hline
\end{tabular}

${ }^{1}$ Statistical comparisons-Wilcoxon $T$ :

\begin{tabular}{lrrr}
\hline & $n$ & $T$ & $P$ \\
\hline$S C-2$ & & & \\
A. Neg. vs. Pos. & 7 & 0 & $<0.01$ \\
B. Neg. vs. Pos. & 9 & 10 & n.s. \\
$S C-8$ & & & \\
C. Neg. vs. Pos. & 7 & 15 & n.s. \\
D. Neg. vs. Pos. & 9 & 18 & n.s. \\
$S C-2$ with $S C-8$ & & & \\
E. Pos. vs. Pos. & 7 & 11 & n.s. \\
F. Pos. vs. Pos. & 9 & 26 & n.s. \\
G. Neg. vs. Neg. & 7 & 1 & $<0.01$ \\
H. Neg. vs. Neg. & 9 & 1 & $<0.01$ \\
J. Facing vs. facing & 7 & 7 & n.s. \\
K. Facing vs. facing & 9 & 17 & n.s. \\
\hline
\end{tabular}

were indisputable facial expressions of emotion. In the smile, the corners of the mouth turn up, and there is usually wrinkling around the eyes. A problem with these children is that most of the time the corners of their mouths turn down. The smile must be superimposed on this (Fig. 3).

In Table 8 we have summarized across the first seven subjects the frequency of the happy and sad expressions for each of the structured situations. Again the paucity of facial expression was remarkable.

On the positive side most of the smiles occurred with two motion stimuli, the vertical bounce $(S C-6 B)$ and the twirling chair $(S C-8 A)$. This is consistent with the observations on positive social interaction in those sequences, summarized in Tables 4 and 5. The highest rates of cry/sad expresions were for situations $S C-2 C$ and $S C-4 A$, in which there was a high degree of physical contact. In the three episodes under $S C-2$ a gradual increase in contact was associated with a gradual increase in the frequency of cry/sad expressions. This was consistent with the analysis of social responses summarized in Tables 1 and 3. The analysis of motor or body movement behavior was in each case consistent with the analysis of facial expression. It is of some interest that in children with so little facial expression that the directions of these positive and negative responses to the different stimuli were so clear.

\section{REPETITIVE BEHAVIOR}

Behaviors have been summarized under the heading of "repetitive" that might be called sterotypy or self-stimulatory behavior. Self-mutilative behavior is included. The amount of time each subject was engaged in performing any of 10 repetitive acts is summarized in Table 9. The first three acts would generally be considered self-aversive, and all of them autistic or self-oriented behavior which could interfere with or prevent the acquisition of socially acceptable or adaptive behavior. Each subject tended to perform only one or a few of these acts, and usually in his own rather unique way. They appeared to be self-programmed. The impetus for these acts seemed to come from within. They were repeated across every stimulus condition, and they appeared to be unrelated to the environment. Hand posturing (Fig. 4) and hand posturing with regard of the hand is clearly stereotypic behavior, and unusual even among retarded children. We have combined data on self-aversive and autistic acts in order to see whether any of the structured situations decreased or increased the amount of time spent in such behavior. Table 10 presents a ranking of the stimulus conditions based on the amount of autistic behavior in which the least mean score was given the rank of 1 . The mean rank score provides a central position from which some stimulus conditions may be seen to be associated with more or less of these acts. The $50 \%$ increase or decrease figures are reference points indicating that the rate of these acts has changed drastically.

The somewhat surprising finding was the clustering of the highest rates of self-aversive/autistic acts in the presence of the familiar person, the mother of five of these seven subjects. This might mean that these acts are called forth by emotion. Another variable was that our adult stranger was an unusually sensitive person, good at working with handicapped children and by contrast with her warm interactions with the children most of the mothers seemed cold and inept. On the other hand this too could have been a consequence of years of interactions of a mother with a highly unresponsive child. One thing was clear, it was not the

Table 6. Facial responses to twirling

\begin{tabular}{cccc}
\hline & \multicolumn{3}{c}{ Smile/happy, f/min } \\
\cline { 2 - 4 } Subject & Sequences $S C-2 A, B, C$ & Twirl & Twirling stopped \\
\hline 1 & 0.0 & 4.3 & 0.0 \\
2 & 0.3 & 3.2 & 0.4 \\
3 & 0.0 & 2.4 & 0.0 \\
4 & 0.0 & 1.0 & 0.0 \\
5 & 0.0 & 0.0 & 0.6 \\
6 & 0.0 & 1.3 & 0.0 \\
8 & 0.0 & 1.8 & 0.0 \\
9 & 0.0 & 1.1 & 1.5 \\
\hline
\end{tabular}

Table 7. Comparison of attention to persons or task-objects ${ }^{1}$

\begin{tabular}{cccc} 
Subject & $\begin{array}{c}\text { Person, } \\
\text { sec/min }\end{array}$ & $\begin{array}{c}\text { Neutral, } \\
\text { sec/min }\end{array}$ & $\begin{array}{c}\text { Task-objects, } \\
\text { sec/min }\end{array}$ \\
\hline$I$ & 3.9 & 2.1 & 53.9 \\
2 & 2.8 & 0.0 & 57.2 \\
3 & 8.5 & 2.7 & 48.6 \\
4 & 0.4 & 7.5 & 52.1 \\
5 & 0.0 & 0.0 & 60.0 \\
6 & 3.8 & 0.0 & 56.2 \\
7 & 22.9 & 0.0 & 37.2 \\
8 & 23.6 & 0.0 & 36.4 \\
9 & 4.3 & 28.3 & 27.5 \\
\hline
\end{tabular}

'Statistical comparisons-Wilcoxon $T$ :

\begin{tabular}{llll}
\hline & $n$ & $T$ & $P$ \\
\hline Attending & & & \\
A. Person vs. Task - object & 7 & 0 & $<0.01$ \\
B. Person vs. Task - object & 9 & 0 & $<0.01$ \\
\hline
\end{tabular}


Table 8. Frequency of emotional expressions ${ }^{1}$

\begin{tabular}{|c|c|c|c|c|c|c|c|c|}
\hline \multirow[t]{2}{*}{ Response } & \multicolumn{8}{|c|}{$\mathrm{f} / \mathrm{min}$} \\
\hline & $\begin{array}{c}S C-1 \\
\text { (alone) }\end{array}$ & $\begin{array}{c}S C-2 A \\
\text { (call) }\end{array}$ & $\begin{array}{l}S C-2 B \\
\text { (walk) }\end{array}$ & $\begin{array}{c}S C-2 C \\
\text { (pat) }\end{array}$ & $\begin{array}{c}S C-3 \\
\text { (xylophone) }\end{array}$ & $\begin{array}{c}S C-4 A \\
\text { (horizontal } \\
\text { holding) }\end{array}$ & $\begin{array}{c}S C-4 B \\
\text { (vertical } \\
\text { holding) }\end{array}$ & $\begin{array}{c}S C-5 \\
\text { (jack-in-box) }\end{array}$ \\
\hline Smile/happy & 0.0 & 0.1 & 0.0 & 0.0 & 0.01 & 0.0 & 0.1 & 0.4 \\
\hline \multirow[t]{2}{*}{ Cry/sad } & 0.0 & 0.6 & 0.8 & $1.2^{1}$ & 0.1 & $2.4^{1}$ & 0.0 & 0.0 \\
\hline & $\begin{array}{l}S C-6 A \\
\text { (swing) }\end{array}$ & $\begin{array}{c}S C-6 B \\
\text { (bounce) }\end{array}$ & $\begin{array}{c}S C-7 A \\
\text { (call) }\end{array}$ & $\begin{array}{l}S C-7 B \\
\text { (walk) }\end{array}$ & $\begin{array}{c}S C-7 C \\
\text { (pat) }\end{array}$ & $\begin{array}{c}S C-7 D \\
\text { (pick up) }\end{array}$ & $\begin{array}{l}S C-8 A \\
\text { (twirl) }\end{array}$ & $\begin{array}{c}S C-8 B \\
\text { (twirl stop) }\end{array}$ \\
\hline Smile/happy & 0.2 & $1.8^{1}$ & 0.3 & 0.0 & 0.7 & 0.7 & $1.7^{1}$ & 0.1 \\
\hline Cry/sad & 0.0 & 0.0 & 0.2 & 0.0 & 0.0 & 0.1 & 0.0 & 0.0 \\
\hline
\end{tabular}

${ }^{1}$ The data are the means of the responses of the first seven subjects.

Table 9. Repetitive or stereotypic behavior

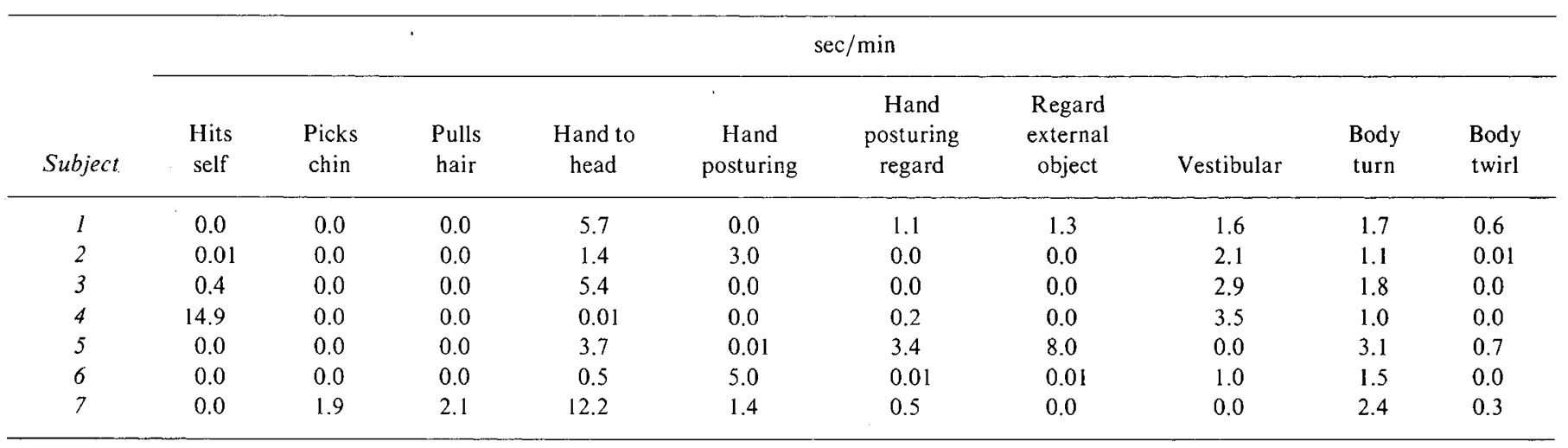

Table 10. Rank order of stimulus conditions in duration of self-aversive or autistic behavior ${ }^{1}$

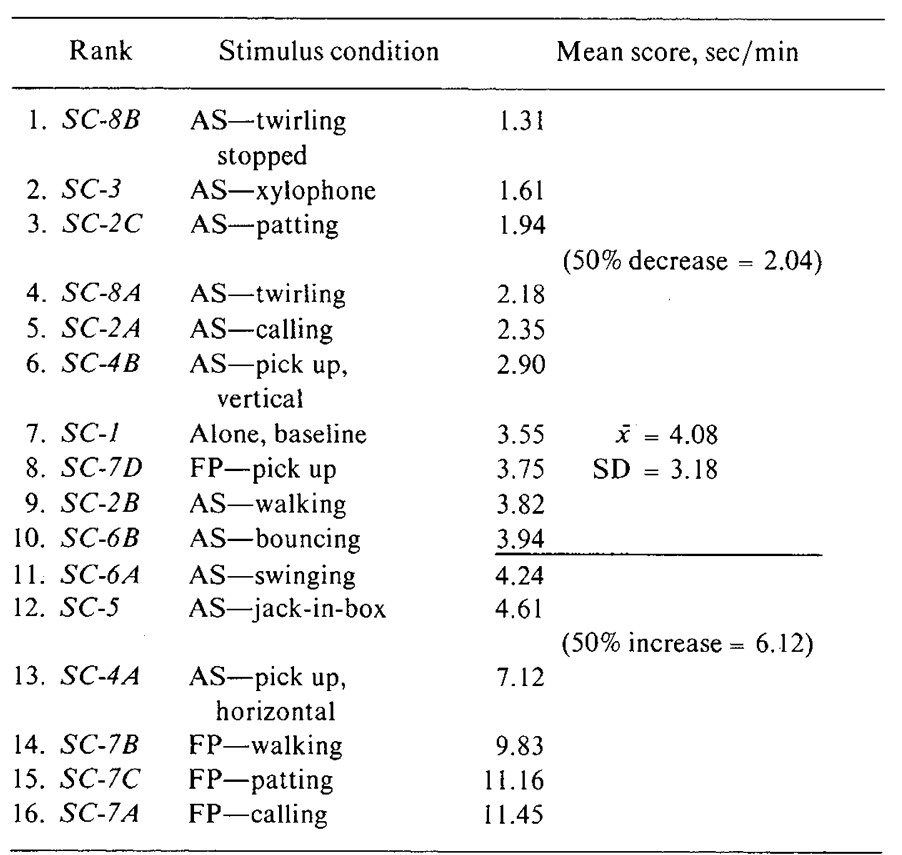

${ }^{1}$ AS: adult stranger; FP: familiar person.

mother's discomfort with the video situation, for these differences were readily observed off camera.

A consistent category of behavior was the turning behavior of these children. These were coded as "body turns" for any turning movement and "body twirls" when a full circle was made in a small area. Movements of the head that seemed to be designed to accomplish the same kind of self-stimulation as the whole body turns were coded as "vestibular." This turning category of behavior was indulged in by each of the seven subjects. This type of activity made up a considerable component of each child's spontaneous behavior.

\section{DISCUSSION}

The data obtained have defined in some quantitative detail a set of behavioral characteristics that make up a behavioral phenotype for the de Lange syndrome. They provide evidence that quantitative descriptions of behavior may be obtained with these techniques in populations of retarded children.

Patients with the de Lange syndrome are nonsocial either with family members or strangers. They reject the usual physical contacts children have with other people. Characteristically they have no speech $(10,14-16)$. They make low pitched, growling or animal-like sounds that are monotonous and without the remarkable variation in sound that characterizes speech or even the normal crying of infants. There have been some previous comments in the literature about these growling, sometimes raucous sounds made by these patients $(7-9,12)$. Among our patients the only two that had any speech at all behaved rather differently than the others in most of the social interactions tested. Nevertheless, even these two patients had very little to say. Patients with this syndrome rarely display emotion. Their faces are usually inexpressive. They have been described as masklike (12). They engage in stereotypic self-stimulatory activity. Certain types of vestibular or kinesthetic stimulation were regularly pleasurable for these patients. In general, the type of stereotypy indulged in by the patient is his own characteristic set of movements. Some of these self-stimulatory repetitive activities appear to be self-aversive. We have previously described self-mutilative behavior in patients 
with this syndrome $(3,15)$. One of the two patients that died during the period covered by this study had developed an increasing pattern of self-mutilative behavior and died in an act that could be interpreted as suicide. The other, the first patient we had reported with self-mutilative activity (15), was committed after the death of his mother to an institution for the retarded, in which he died under circumstances that could be interpreted as murder by another patient. These acts appear to be relevant to the behavioral phenotype of these patients.

The syndrome described by Cornelia de Lange in 1933 (4) is among the more common malformation syndromes. It is characterized by a complex of malformations, many of them relatively minor which together permit its ready recognition. Major defects include retardation of growth and mental development. Although the diagnosis of this disorder does not usually present a challenge to those with experience with the syndrome, it may sometimes be difficult, particularly in infancy (13). Unfortunately, there is no single feature that makes the diagnosis and no chemical or cytogenetic test for the syndrome. Dermatoglyphic and roentgenologic characteristics may help (1). The addition of behavioral characteristics to the phenotype may sometimes be useful in diagnosis.

Behavior has only recently been considered in the patient with the de Lange syndrome $(3,11,12,15)$. In a recent report, Greenberg and Coleman (7) described hyperactive behavior in nine patients with the de Lange syndrome in whom levels of serotonin in the blood were low. Stereotypic and self-mutilative behavior were also observed in this series. Most of their patients were also characterized as displaying outward-directed destructive and aggressive behavior. Two of our patients had speech. Others $(8,9)$ have reported patients with speech. We have thought that the development of speech, particularly if it is associated with a less severe degree of mental retardation (9), might indicate heterogeneity among patients with the somatic features of the de Lange syndrome.

The quantitative description of behavior in a dysmorphic syndrome provides a background for studies on other syndromes. We have been impressed that there are other syndromes in which characteristic patterns of behavior are seen. This is of course true of the Lesch-Nyhan syndrome. It appears also to be the case in the hypercalcemia syndrome and in the Prader-Willi syndrome. The precise definition of patterns of quite different behavior in a group of quite distinct disorders with abnormal morphology or biochemistry could provide clues as to the genetics of behavior. Anatomic, chemical, and physiologic correlates of behavior within the central nervous system are largely unknown. The study of unusual disorders could, as in other areas, lead to advances in understandings of these relationships.

The assembly of behavioral information on patients with the de Lange syndrome could be helpful to physicians in counseling of parents or others involved in the care of these children. The thing parents need and want to know after the diagnosis of a child with a specific syndrome is what to expect in the way of behavior. The nosology is of interest to physicians and scholars. Parents are more concerned with the prognosis as to what the child will be like. If we review our information on this subject it is clear that in most instances we simply do not know. We can now advise parents of children with the de Lange syndrome not to expect the usual forms of reciprocation of love and affection. A parent who knows that the infant is likely to arch his back and struggle when she picks him up to cuddle him is less likely to interpret this as a personal rejection.
Just knowing that a form of behavior is a characteristic of a disorder is sometimes helpful in living with it. In dealing with infants with the de Lange syndrome it may be that the use of vigorous vestibular or motion stimulation will not only provide a pleasurable experience for the child but might permit the introduction of techniques of behavioral modification.

\section{SUMMARY}

A research methodology has been developed for obtaining quantitative behavioral data using videotape. The method has been applied to the study of a series of patients with the de Lange syndrome. A behavioral phenotype has been defined for these patients. They were characterized as avoiding and rejecting social interaction with either strangers or familiar persons such as the mother, and in particular rejection of physical contact with other persons. They rarely exhibited facial expressions of emotion. They engaged in stereotypic activity of a self-stimulatory and sometimes self-mutilative nature. Pleasurable reactions were obtained to vestibular or motion stimuli.

\section{REFERENCES AND NOTES}

1. Berg, J. M., McCreary, B. D., Ridler, M. A. C., and Smith, G. F.: The de Lange Syndrome, Institute for Research into Mental Retardation, Monograph No. 2 (Pergamon Press, New York, 1970)

2. Blurton-Jones, N.: Ethological Studies of Child Behavior (Cambridge University Press, Cambridge, 1972)

3. Bryson, Y., Sakati, N., Nyhan, W. L., and Fish, C. H.: Self-mutilative behavior in the Cornelia de Lange syndrome. Am. J. Mental Def., 76: 319 (1971).

4. de Lange, C.: Sur un type nouveau de degeneration (typus amstelodamensis). Arch. Med. Enfants, 36: 713 (1933).

5. Ekman, P., and Friesen, W. V.: Measuring facial movements. J. Environment. Psychol. Nonverb. Behav., Vol. 1 (1976).

6. Ekman, P., Friesen, W. V., and Taussig, T.: VID-R and SCAN: Tools and methods for the automated analysis of visual records. In: G. Gerbner, $O$. Holsti, K. Krippendorff, W. Paisley, and P. Stone: Analysis of Communication Content, pp. 297-312, (Wiley, New York, 1969).

7. Greenberg, A., and Coleman, M.: Depressed whole blood serotonin levels associated with behavioral abnormalities in the de Lange syndrome. Pediatrics, 51: 720 (1973)

8. McArthur, R. G., and Edwards, J. H.: de Lange syndrome: Report of 20 cases. Can. Med. Ass. J., 96: 1185 (1967)

9. Mclntyre, M. S., and Eisen, J. D.: The Cornelia de Lange syndrome-A case report with mild mental retardation. Amer. J. Ment. Defic., 70: 438 (1965)

10. Nicholson, D. H., and Goldberg, M. F.: Ocular abnormalities in the de Lange syndrome. Arch. Ophthalmol., 75: 214 (1966)

11. Nyhan, W. L.: Behavioral phenotypes in organic genetic disease. Presidential address to the Society for Pediatric Research, May 1, 1971. Pediat. Res., 6: 1 (1972).

12. Opitz, J., and Groose, F.: Discussion on the de Lange syndrome. In: S. S. Gellis: Yearbook of Pediatrics, pp. 486-489 (Yearbook Medical Publishers, Chicago, 1971).

13. Pashayan, H., Levy, E. P., Fraser, F. C.: Can the de Lange syndrome always be diagnosed at birth? Pediatrics, 46: 940 (1970).

14. Schuster, D. S., and Johnson, S. A. M.: Cutaneous manifestations of the Cornelia de Lange syndrome. Arch. Dermatol., 93: 702 (1966).

15. Shear, C. S., Nyhan, W. L., Kirman, B. H., and Stern, J.: Self-mutilative behavior as a feature of the de Lange syndrome. J. Pediat., 78: 506 (1971).

16. Silver, H. K.: The de Lange syndrome. Amer. J. Dis. Child., 108: 523, (1964).

17. The present address of Drs. Harold G. Johnson, Paul Ekman, and Wallace Friesen is: Human Interaction and Conflict Laboratory, University of California, San Francisco, California.

18. The present address of Dr. Carol Shear is: Mailman Center, Department of Pediatrics, University of Miami, Florida.

19. This research was aided by grants from the Johnson and Johnson Foundation for Pediatric Service and National Institutes of Health Contract 2794, National Institute of Child Health and Development.

20. Requests for reprints should be addressed to: W. L. Nyhan, M.D., Department of Pediatrics, University of California, San Diego, La Jolla, Calif. 92093 (USA).

21. Accepted for publication May 14, 1976. 